This is a post-print version of the following article: Rovira-Esteva, Sara; Orero, Pilar. (2011). A contrastive analysis of the main benchmarking tools for research assessment in translation and interpreting: the Spanish approach. Perspectives, 19(3): 233-251.

http://dx.doi.org/10.1080/0907676X.2011.590214

\title{
A Contrastive Analysis of the Main Benchmarking Tools for Research Assessment in Translation and Interpreting: the Spanish Approach.
}

\section{Sara Rovira-Esteva (1) \& Pilar Orero (2) \\ Departament de Traducció i Interpretació, Universitat Autònoma de Barcelona, Spain}

\section{Abstract}

Research assessment has become one of the most taxing exercises that scholars have to endure on a regular basis. Publications seem to be the currency used nowadays for everything from: getting funds for a PhD, to gaining access to an academic post and indeed promotion. Research assessment results are also of key importance in university departments, as funding and resources are increasingly linked to research results. In the Department of Translation and Interpreting at the Universitat Autònoma de Barcelona a pro-active policy has been adopted with the aim of improving results from research activities at all levels. Within this context we put together a list of T\&l (Translation and Interpreting) journals and joined efforts with our colleagues in the Library of Humanities of our university to include information about where these journals are indexed. While gathering the information for the list certain doubts, questions, and patterns emerged, at the same time we were continuously surprised by the results that emerged during the course of the assessment exercise.

Based on the data collected regarding T\&I journals along with the existing assessment requirements made public by the various Catalan and Spanish quality agencies, we analysed the objective parameters that are taken into consideration when evaluating research. In writing this article we had three main goals: first, to gain a deeper understanding of the current research practices concerning publications within T\&l; second, to carry out a bottom-up analysis and offer concrete data concerning average number of pages, average number of authors per article, authors ordering and research output format and performance of scholars affiliated to Spanish universities in terms of high impact contributions. Finally, we wanted to reflect upon the real life application of the common assessment criteria.

Keywords: Bibliometrics, Scientometrics, Translation and Interpreting, Research, Impact, Quality Assessment, T\&I Journals 


\section{Introduction}

'Publish or Perish' (Harzing 2010b) is now a much maligned term which is fast spreading among countries where the university system is based on research achievement. 'Publish or Perish' (PoP) refers to the pressure faced by researchers to publish work in order to enter and/or maintain and secure a job within academia. Many issues are raised when dealing with a policy which promotes results that are easy to quantify but hard to evaluate in terms of quality.

The focus of research output these days seems to be limited to getting articles published in indexed journals and presenting your work at international conferences. Both of these activities have to be of a high quality, and in Europe for example, in order to ensure these standards are achieved and maintained, evaluation boards have been established at all levels. What seems to be a neat, tidy and well accepted practice in the world of Science research has become a self-perpetuating hobbyhorse in the field of Humanities and Social Sciences.

Be as it may, research assessment exercises are here to stay and the situation may get even more complicated with the introduction of a new research concept, that of 'impact' (Collini 2009, Harzing 2010a). Hence the only positive approach to survival in the new university funding order - from the point of view of both the institution and the individual's career - is to come to terms with the evaluation standards, criteria and practices. While it may be hard to agree with the logic behind quality evaluation in the field of Humanities, it is paramount to understand how the system works it in order to have fair play, and a successful career.

Research evaluation is clearly not homogenously assessed worldwide. In the US scientific output is assessed for tenure as a matter of course - and while other countries such as Spain, South Africa and the UK are following suit other countries are lagging far behind. That said the whiff of "impact" is beginning to spread across the planet. 
Working in the field of Translation and Interpreting Studies, as early as 1995 Franz Pöchhacker used bibliometrics to map the development of the field of Interpreting Studies (IS). Daniel Gile (2000 and 2005) also used this new research assessment tool to draft a history of research in IS. The same analysis was used by Franco \& Orero (2005) to study the rise and trends of Audiovisual Translation research as an independent field within Translation Studies (TS). While bibliometrics seems to be a thriving field within IS (Grbic 2007, Grbic \& Pöllabauer 2008a, 2008b \& 2009) little has been done in the realm of TS.

This article is the result of many months of data gathering from two different sources: on the one hand we looked at three objective indicators used for assessment by several Spanish and Catalan quality agencies (RoviraEsteva and Orero forthcoming). On the other, we gathered a list of journals with the many indexical features required by evaluation agencies. The methodology used for the analysis here is bottom up - using the published criteria as a starting point, then analysing a set of indexed publications combined with available, existing research assessment results - we can thus offer an analysis of the published assessment criteria and their application in actual research output. The work flow is represented in figure 1 :

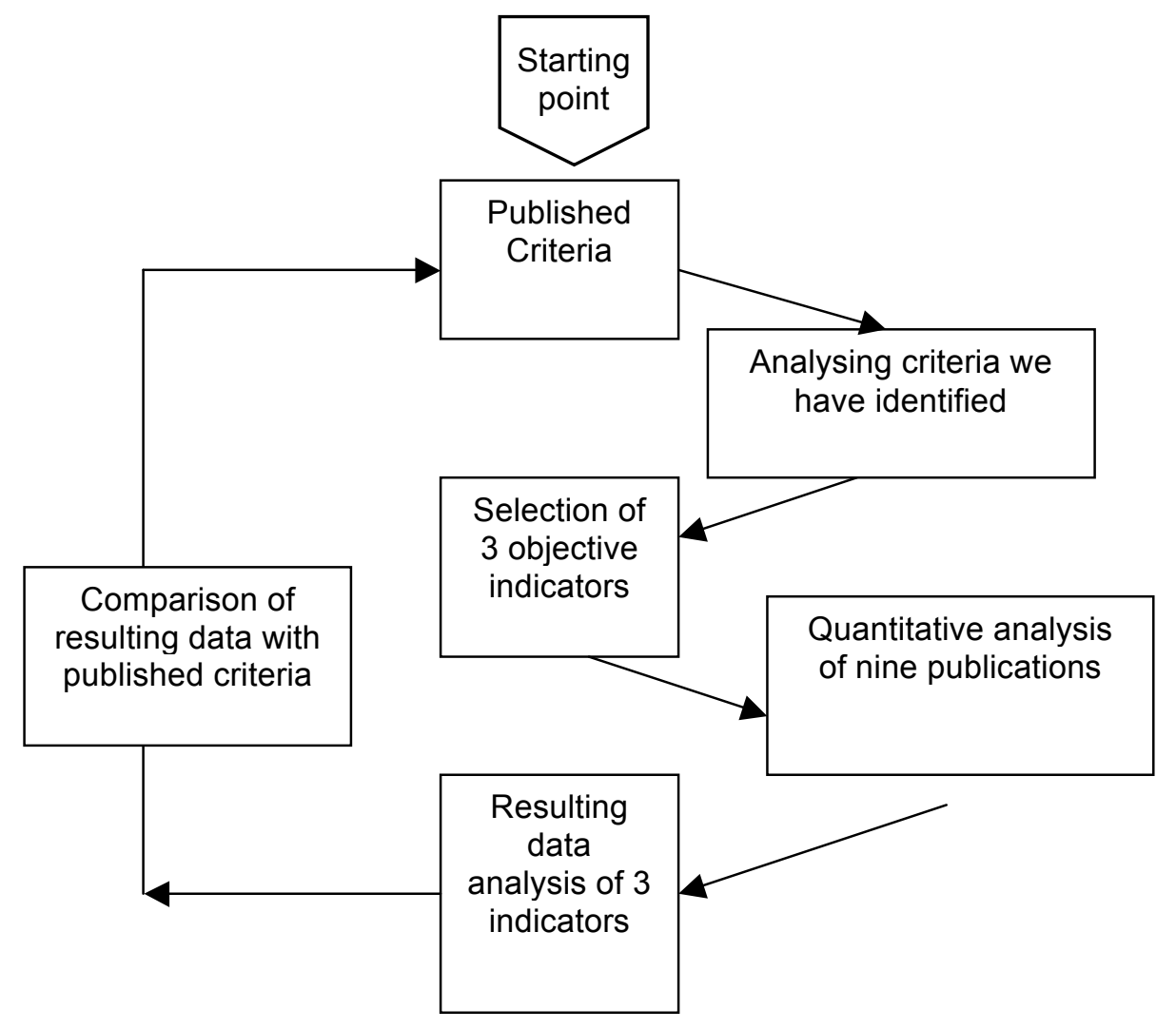


Figure 1. Flow of analysis carried out for this article

This analysis, which is based on published assessment criteria and empirical analysis of the results, should shed some light on the prevailing subconscious, but commonly agreed assessment benchmarks, which have been the norm for years. The article then puts into practice its findings, applying the resulting data to the outcome of two specific research evaluations. This was undertaken in order to determine to what extent the actual evaluations in question follow or diverge from the empirical data gathered by us. It also examines the arguments that were put forward to justify certain evaluator decisions.

The article concludes with some reflections regarding the possible actions which could be taken to objectively improve the process and thereby reduce the criticisms of the system (Collini, 2009; Lamont 2009; Rovira-Esteva \& Orero forthcoming).

Ultimately the aim of this article on T\&I bibliometrics is to provide both researchers and evaluators with more concrete guidelines based on empirical data concerning different aspects of research quality assessment. Data is gathered from: lists of indexed journals, number of authors, author ordering, number of pages, research output format, and citations that rate the best.

\section{The corpus}

Without exception, evaluation agencies highly value articles published in indexed journals. All Spanish evaluation agencies reference, in the first instance, Journal Citation Reports (JCR), Social Sciences Citation Index (SSCI) and Arts, and Humanities Citation Index $(\mathrm{AHCl})$. As a secondary resource, they also mention other similar sources, relevant to each field of study, that may be considered for evaluation, such as: Bibliographie Linguistique $(B L)$, Bibliography of the History of Arts (RLG), European Reference Index for the Humanities (ERIH), FRANCIS, Historical Abstracts, Index Islamicus, International Bibliography of Periodical Literature in Humanities and Social Sciences (IBZ), International Bibliography of the Social Sciences (IBSS), International Medieval 
Bibliography, Library and Information Science Abstracts (LISA), Philosopher's Index, Répertoire Bibliographique de Louvain, RILMS Abstracts of Music Literature and SCOPUS, among other. Since no index or database exist for T\&I Studies, the corpus for the present study was chosen from all the journals on T\&I Studies and related areas (3) indexed either in the Social Science Citation Index or the Arts and Humanities Citation Index - as these are the most highly regarded indexes in Social Sciences and Humanities, respectively, and therefore may be considered as high impact journals by evaluators (4). Although the scope of the article is not to question the assessor's ranking of indexes, there is a requirement for further work in this direction as there is little agreement regarding the adequacy of any of the indexes in question. More unclear is the status of commercially available citation analysis tools versus free on line tools such as Google Scholar (Harzing 2010a).

In order to quantify and understand the status of T\&I Studies journals in international indexes and databases the authors drafted a list of 38 journals in T\&I (see Rovira-Esteva and Orero forthcoming). It became clear that despite their multidisciplinary approach and content, T\&I journals are, practically speaking, missing from the ISI databases, i.e. $\mathrm{AHCl}$ and $\mathrm{SCCl}$. Given the low representation of T\&I journals in these indexes, we decided to search again, including altogether 141 journals covering other "related areas" -mainly language as a form of communication - as well as additional indexes and databases. The objective was two-fold. First, to show that multidisciplinary journals - or those with a broader scope - are more likely to be indexed than those focusing exclusively on T\&I Studies. Second, to highlight the fact that when assessing research output quality within our field of studies, none of the existing indexes or databases adequately represents this field, and consequently an index of our own is urgently needed. The low overall representation in indexes of high quality journals such as Target or Linguistica Antverpiensia New Series, and most online journals shows how inaccurate and incomplete the current system actually is.

The list of evaluated journals is as follows:

- Across Languages and Cultures. A Multidisciplinary Journal for Translation and Interpreting Studies (AHCI/SSCI)

- Interpreter and Translator Trainer (AHCl) 
- Language \& Communication. An Interdisciplinary Journal (SSCI)

- Language and Intercultural communication (AHCl)

- Meta. Journal des Traducteurs (AHCl)

- Multilingua. Journal of Cross-cultural and Interlanguage Communication (AHCI/SSCl)

- Perspectives. Studies in Translatology (AHCl)

- Translation Review (AHCl)

- Translator. Studies in Intercultural Communication (AHCI/SSCl)

After selecting the following three years (2007, 2008 and 2009) back catalogue for the above mentioned nine journals, a corpus of 71 volumes was gathered containing a total of 495 papers (see table 1 for results) (5). This corpus was created to reverse-engineer or invert the process of evaluation, in order to examine the resultant data and to draw conclusions. We decided to check in a quantitative way those indicators that can be easily measured: number of pages per article, listed order and number of authors, as well as the prestige of the publishing house. The results gathered are objective indicators and a step forward towards understanding the criteria of evaluation that have proven successful. We hence move forward from intuition and assumptions, to opinion based on empirically gathered data, and although we have performed the analysis from Spanish and Catalan perspective, the same study can be replicated in any country, as we are dealing with international journals.

While three indicators are perhaps a small set of test indicators, they should be considered as a starting point in the journey towards understanding local assessment trends which reflect existing assessment practices.

\begin{tabular}{|c|c|c|c|c|c|c|}
\hline Journal's Title & $\begin{array}{c}\text { Publishin } \\
\text { g House }\end{array}$ & $\begin{array}{l}\text { Avg. } \\
\text { No. } \\
\text { Author } \\
\text { s }\end{array}$ & $\begin{array}{l}\text { Alphab } \\
\text { etical } \\
\text { Order( } \\
6)\end{array}$ & $\begin{array}{l}\text { Avg. } \\
\text { No. } \\
\text { Page } \\
\text { s }\end{array}$ & $\begin{array}{c}\text { No. } \\
\text { Author } \\
\text { s from } \\
\text { Spanis } \\
\text { h Univ. } \\
\text { (7) }\end{array}$ & $\begin{array}{c}\text { Total } \\
\text { number } \\
\text { of } \\
\text { articles } \\
2007-09\end{array}$ \\
\hline $\begin{array}{l}\text { Across Languages } \\
\text { and Cultures. A } \\
\text { Multidisciplinary } \\
\text { Journal for } \\
\text { Translation and }\end{array}$ & $\begin{array}{l}\text { Hungaria } \\
n \\
\text { Academy } \\
\text { of } \\
\text { Sciences }\end{array}$ & 1.2 & $\begin{array}{c}3 \text { yes/ } \\
2 \text { no }\end{array}$ & 19.6 & $\begin{array}{c}4 \\
(12 \%)\end{array}$ & 31 \\
\hline
\end{tabular}




\begin{tabular}{|c|c|c|c|c|c|c|}
\hline \\
\hline $\begin{array}{l}\text { Interpreter and } \\
\text { Translator Trainer }\end{array}$ & $\begin{array}{c}\text { St. } \\
\text { Jerome } \\
\text { Publishin } \\
\text { g } \\
\end{array}$ & 1.3 & $\begin{array}{c}6 \text { yes } / \\
3 \text { no }\end{array}$ & 23.1 & $\begin{array}{c}8 \\
(23.5 \% \\
\quad)\end{array}$ & 34 \\
\hline $\begin{array}{c}\text { Language \& } \\
\text { Communication. An } \\
\text { Interdisciplinary } \\
\text { Journal }\end{array}$ & Elsevier & 1.1 & $\begin{array}{l}4 \text { yes } / \\
2 \text { no }\end{array}$ & 18.3 & $\begin{array}{c}1 \\
(15 \%)\end{array}$ & 63 \\
\hline $\begin{array}{l}\text { Language and } \\
\text { Intercultural } \\
\text { Communication }\end{array}$ & $\begin{array}{c}\text { Multilingu } \\
\text { al } \\
\text { Matters/ } \\
\text { Routledg } \\
\text { e }\end{array}$ & 1.2 & $\begin{array}{c}5 \text { yes / } \\
4 \text { no }\end{array}$ & 14.8 & $\begin{array}{c}6 \\
(12.5 \% \\
\quad)\end{array}$ & 48 \\
\hline $\begin{array}{l}\text { Meta. Journal des } \\
\text { Traducteurs }\end{array}$ & $\begin{array}{c}\text { Les } \\
\text { Presses } \\
\text { de } \\
\text { l'Universit } \\
\text { é de } \\
\text { Montréal }\end{array}$ & 1.2 & $\begin{array}{l}16 \text { yes } \\
/ 11 \text { no }\end{array}$ & 16.4 & $\begin{array}{c}19 \\
(13.3 \% \\
\quad)\end{array}$ & 142 \\
\hline $\begin{array}{c}\text { Multilingua. Journal } \\
\text { of Cross-cultural and } \\
\text { Interlanguage } \\
\text { Communication }\end{array}$ & $\begin{array}{c}\text { Walter de } \\
\text { Gruyter }\end{array}$ & 1.4 & $\begin{array}{l}6 \text { yes/ } \\
10 \text { no }\end{array}$ & 24.6 & $0(0 \%)$ & 45 \\
\hline $\begin{array}{l}\text { Perspectives. Studies } \\
\text { in Translatology }\end{array}$ & $\begin{array}{c}\text { Multilingu } \\
\text { al } \\
\text { Matters/ } \\
\text { Routledg } \\
\text { e }\end{array}$ & 1.3 & $\begin{array}{c}2 \text { yes / } \\
6 \text { no }\end{array}$ & 15.1 & $\begin{array}{c}8 \\
(17.7 \% \\
\quad)\end{array}$ & 45 \\
\hline Translation Review & $\begin{array}{l}\text { University } \\
\text { of Texas }\end{array}$ & 1.03 & 1 no & 7.5 & $0(0 \%)$ & 32 \\
\hline $\begin{array}{c}\text { Translator. Studies in } \\
\text { Intercultural } \\
\text { Communication }\end{array}$ & $\begin{array}{c}\text { St. } \\
\text { Jerome } \\
\text { Publishin } \\
\text { g }\end{array}$ & 1.09 & $\begin{array}{c}2 \text { yes } / \\
3 \text { no }\end{array}$ & 19.9 & $5(9 \%)$ & 55 \\
\hline TOTAL & & 1.18 & $\begin{array}{c}45 \text { yes } \\
(51.7 \% \\
) / 42 \\
\text { no } \\
(48.2 \% \\
\quad) \\
\end{array}$ & 17.7 & $\begin{array}{c}51 \\
(10.3 \% \\
\quad)\end{array}$ & 495 \\
\hline
\end{tabular}

Table 1. Results from averages gathered concerning three objective parameters

As we can see, all nine journals are from either academic presses - Hungarian Academy of Sciences, Les Presses de l'Université de Montréal and the University of Texas at Dallas - or prestigious independent academic publishing 
houses: St. Jerome Publishing, Elsevier, Multilingual Matters/Routledge (8) and Walter de Gruyter. Though it may be interesting to compare quality and citation impact between publications from academic presses against independent publishing (Aguirre 2009, Fernández 2009) it will not be pursued in this article.

\section{Number of authors in Translation Studies journals}

The number of authors considered to be desirable in Translation Studies, as a topic, is rarely overtly discussed. On the one hand, we are advised to pursue interdisciplinary or multidisciplinary research, and as such we need research teams with a considerable number of members from various backgrounds. On the other hand, it would be advantageous to know what might be considered by evaluators as too high a number. This is however an open issue in general terms and not just in T \& I Studies. While in Psychology it may be a common practise to work in large teams, in Biology a small team of three people will generally suffice to validate or replicate an existing piece of work (Kissan, Laband and Patil, 2005).

Although we have a vague idea of what is considered average in our discipline, to our knowledge - a maximum of two - no empirical data has been published on this subject. Given the nature of T\&I Studies and their scope (9), the number of researchers will continue to vary significantly, but be as it may, if there is an internal recommendation for evaluators, this should be made public in order to be fair.

While not conclusive, we conducted a first approximation analysis of the average number of authors per publication in a sample of T\&I journals. From the list of nine journals across the selected years we systematically checked the number of authors per research article (editorials and review articles excluded). The resulting data -1.18 authors per article - is based on an analysis of almost 500 articles. This illustrates how in T\&I Studies research is still carried out individually, or in pairs - or at least published in this way. This fact could be a strategy to score maximum impact, or most probably reflects the nature of research in our field. This outcome is backed up by results obtained by Cronin (2003, p. 11), who studied this factor in different fields concluding that the academic historians - and researchers in the field of Humanities generally write alone, thereby contrasting with the levels of co-authorship that can be 
seen in some other fields such as Science. This finding has been confirmed by Harzing (2010a) (see figure 2), although her figure for Linguistics is slightly higher than the one we have encountered for T\&I Studies.

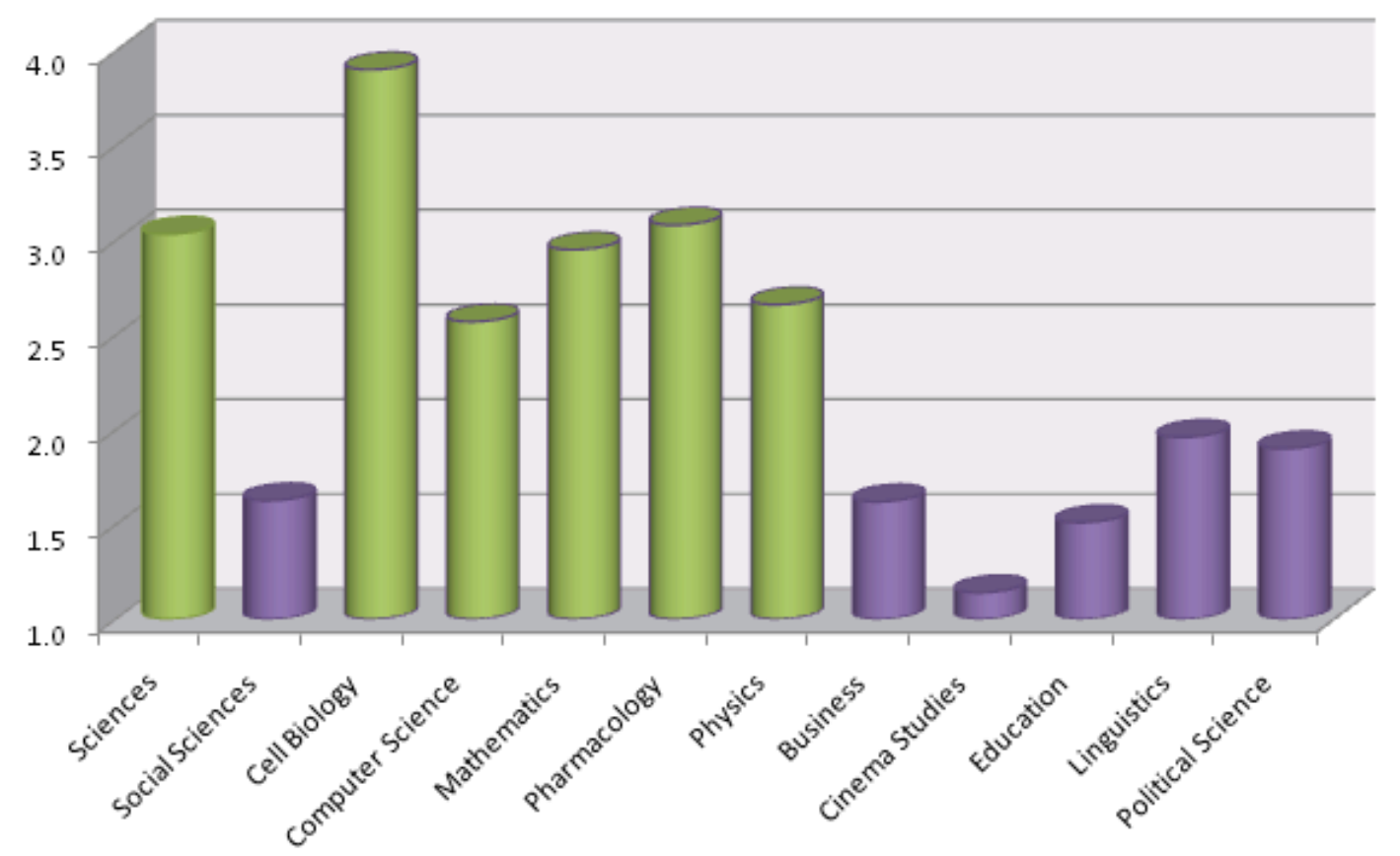

Fig. 2 Average number of authors per paper in different disciplines

It would also be interesting to find out if the figures represented in the table above change according to country of origin and/or line of research. Perhaps there has been some evolution over time. It may also be possible that these figures increase when researchers are members of large research groups, but, as these particular questions do not fall within the scope of the present paper, we shall leave them for future research.

Fry et al (2009, p. 34) affirm that "Collaboration and co-authorship has increased greatly over recent years, mainly through a shift in emphasis amongst funding bodies. The number of co-authored papers has levelled off in recent years, but remains high". Nevertheless, despite an increase in research teams and funded projects within T\&I Studies, at least in Spain, we have not noticed within our corpus a significant increase in the number of authors per article in the last three years. Apparently our area is not following the general trend in the field of Humanities. 
This contradiction in T\&I Studies may be due, at least in Catalonia and Spain, because of explicit benchmarking criteria. Assessment guidelines analysed in our study, i.e. AQU 2007 and ANECA 2008 illustrate that a negative factor might be applied when evaluating cases where the number of authors exceeds that which is deemed as average in the field, which in turn, gives rise to two issues.

The first is that although it counts as a negative factor, the reality is that some papers are submitted by teams. The second issue is that the average trend over the period analysed seems fixed at 1.18 authors. If this is what is expected, and a higher number of authors is to be discriminated against, a bias towards individual research now seems to be the firmly established norm. These results would also indicate that short-term change is unlikely in this regard even if multidisciplinary research is considered as a positive factor.

Beyond the analysis and the explicit contradiction regarding multidisciplinarity and no. of authors, previously mentioned, there is another related issue that deserves attention: there seems to be a further contradiction between established number of authors and citation success - which in itself is an index for impact - as Fry et al (2009, pp. 34-5) comment "Despite some disagreement, there is evidence that co-authorship gains more citations than single authored papers and collaboration with an author from another country increases it more." Hence even within what may seem as a basic and objective evaluation element, there is ample room for interpretation and consequently there is opportunity for improvement by agencies when they make public their criteria in this regard.

\section{Author Order}

While the American Psychological Association has a formal policy on author order that states: "Credit is assigned to those who have contributed to a publication, in proportion to their contribution, and only to these... The experimenter or author who has made the major contribution to a publication is identified as the first listed" (Over and Smallman 1973, p.161). The situation in T\&I Studies in this respect is less clear, but we are not alone. Engers et al (1999) and Kissan, Laband and Patil (2005) have previously pointed at the lack 
of consistency in the manner in which author orderings are assigned. Though previous studies such as Engers et al (1999) looked at the field of Economics, they came up with interesting conclusions, such as; author order is not a good indicator of research input.

The use of a non alphabetical name order convention seems to imply that the author who is listed first has actually contributed more, and should receive a greater share of the credit. On the other hand, conforming to an alphabetical ordering may also imply that the first author, in that instance, might have actually contributed more, but it is not conclusive. In such an environment, Engers et al (ibid) show how the alphabetical norm has emerged as a balanced solution but also how quality of research increases if authors are compelled to use a non alphabetized listing of contributions. The explanation for this quality leap is simply that authors will apply more effort in order to have a higher priority listing, which in turn results in higher quality research output.

Kissan, Laband and Patil (2005, p. 545) found that "the rate of alphabetization increases with the stringency with which papers are accepted for publication. Second, conditional on clearing the publication hurdle, quality increases with alphabetization. These findings arise because increases in the publication hurdle make it more likely that authors will exceed this threshold only when both contribute a high amount. This, in turn, leads to roughly equal contributions (alphabetization) and also generates a positive correlation between alphabetization and quality".

Although the alphabetical analysis in the case of two author publications may lack validity - given the fact that the order may be by chance, or may hide the actual share of the first author work - we have followed scientometric analysis standards. This analysis of author order measurement may be regarded as an academic exercise, but let's not forget that this has been evaluated, and is in practice accepted as valid in related disciplines in the Social Sciences and Humanities where their publishing pattern also approximates the one/two author rate.

As far as author listing in T\&I Studies, we have found that an alphabetical order is followed in slightly over half of the cases $(51.7 \%)$ against $(48.2 \%)$ where it is not. Perhaps it would be advisable for authors to clearly state the criterion followed in a footnote for assessment purposes. This could be a useful 
approach when two people establish a publishing relationship and have several works published in both names: but they take turns as to who signs first in order to guarantee assessment equality. It can also be the case that authors negotiate different orderings each time they write a joint paper according to their assessment needs (10).

As with the optimal number of authors, alphabetical ordering best practice should be a clear benchmark made public by agencies for the field of T\&I Studies, since the two-author tandem is a common occurrence and could lead to a variety of misunderstandings.

\section{Number of pages}

Assessing the quality of a paper based on the number of pages is far from ideal or conclusive. To start with, some publisher style sheets, or academic assessments, consider words as the unit of measurement, others count in pages. In addition, layout and typographic elements vary from one journal to another, and while Across Languages and Cultures. A Multidisciplinary Journal for Translation and Interpreting Studies requires in the style sheet submissions between 5,000-10,000 words in length, both Language and Intercultural Communication and Perspectives. Studies in Translatology state that papers should not normally exceed 7,000 words.

Other studies, such as Becher \& Trowler (2001) have shed some light on the issue regarding the number of words and the frequency of publications, as well as the type or format of the publication by fields of research which is an issue addressed in the next section.

Biologists, write one to two articles a year of around four to six thousand words, with the pressure to occasionally produce a twenty thousand word monograph. Specialisms within biology, such as biochemistry, ten or more papers of less than two thousand words, with multiple authorship. Mechanical engineers, a career total of thirty to sixty papers of around four to six thousand words (yearly total of one or two papers), with a lot of additional output in the form of consultancy and reports. Chemistry, a yearly output of ten to twelve papers of usually less than four thousand words, with multiple authors. Mathematics, fewer co-authors and a yearly output of around six papers of six to eight thousand words each. Active economists, if not writing a book, then two to four papers a year with an upper limit of around eight thousand words. Historians and modern linguists, an annual output of eight to twelve thousand words, while also working on a book. (Becher \& Trowler 2001, p. 113) 
In our study we have found that the average number of pages per article varies from one journal to another; mostly ranging from 15 to 25, so anything in between should be considered as standard within our area of research. The only journal that shows a different figure is Translation Review, with an average page count below the rest (7.5\% fewer pages), however it should be noted that this journal is also slightly different from the rest in terms of style, content and academic discourse - veering towards translation from a literary perspective rather than research.

For this quality indicator, the Catalan agency AQU clearly mentions that the minimum requirement for a quality article is 10 pages (AQU 2007, p.7), which in general terms conforms to the actual practices observed.

\section{Research output format}

In the field of T\&I, articles are one of the many research outputs. Fry et al (2009, p. 5) found that "there are discernable differences between disciplines with regard to predominant modes of dissemination and publication, and the rate and speed at which they publish.(11) Different disciplines also produce and publish different types of outputs from datasets and conference proceedings to monographs. It is important to note, therefore, that academic knowledge production and dissemination should not be seen only in terms of published research, especially in applied research areas". In addition, a recent study for the Arts and Humanities Research Council (2008) on the economic impact of UK Arts and Humanities found that

Typical activities of Arts and Humanities academics include researching all the various dimensions of culture and the arts; publishing the fruits of such research in books, journal articles, essays in edited collections or in promulgating them in practice-led outputs in the visual and performing arts, or in design; engaging in dissemination (including contributions to press, radio and TV); engaging in specific knowledge transfer activities, such as exhibitions, public policies development or business improvements; and teaching and supervising arts and humanities undergraduates and postgraduates". (AHRC 2008, p. 9)

In the case of Spain and Catalonia, research contributions published in the form of book chapters is an area of some controversy in our field of research. 
Indexed articles have now taken the lead in terms of academic assessment while - more traditional - contributions such as a books or book chapters have been demoted to the background. We find for example in the Catalan quality agency the cryptic sentence "Quality books may be assimilated to articles in specific fields" (AQU 2008, p. 4) with no further clarification.(12) Conversely, there seems to remain some places in Europe where in the field of the Humanities and Social Sciences a published book remains the standard minimum requirement for promotion and tenure, as is the case in Poland and Germany, and while publication in international refereed print journals is valued, it is not deemed an adequate foundation on which to base an academic career (Kratoska 2009, p. 3).

To see to what extent this is true, in our field of study, we have examined more than 300 reference lists included in articles published in T\&I academic journals to quantify the percentages of total references represented by the various kinds of contributions (see results in table 2). From the previous list of nine indexed journals we have selected those specifically devoted to T\&l Studies and with a minimum of ten years of publishing history with the aim of obtaining diachronic comparative data (2000, 2005 and 2009).(13) We have thus obtained the following list:

- Across languages and Cultures. A multidisciplinary Journal for Translation and Interpreting Studies,

- Interpreter and Translator Trainer,

- Meta. Journal des Traducteurs,

- Perspectives. Studies in Translatology and

- Translator. Studies in Intercultural Communication.

In our analysis, data extraction was only carried out from research articles (editorials, presentations, interviews, conference reports and book reviews were excluded). We grouped references in four main categories: articles published in academic journals (both in paper or electronic format); book chapters (including prologues and introductions); whole books (both being primary and secondary sources); and other (chiefly consisting of $\mathrm{PhD}$ thesis, MA dissertations, proceedings, internet sites, technical reports and press articles). 


\begin{tabular}{|c|c|c|c|c|c|c|}
\hline Journal's Title & Year & Articles & $\begin{array}{c}\text { Book } \\
\text { Chapters }\end{array}$ & Books & Other & $\begin{array}{c}\text { Total } \\
\text { number of } \\
\text { references }\end{array}$ \\
\hline \multirow{4}{*}{$\begin{array}{c}\text { Across languages and } \\
\text { Cultures. A } \\
\text { multidisciplinary } \\
\text { Journal for Translation } \\
\text { and Interpreting } \\
\text { Studies } \\
\text { (total }=35 \text { articles*) }\end{array}$} & 2000 & 36 & 42 & 90 & 11 & 179 \\
\hline & 2005 & 54 & 57 & 118 & 20 & 249 \\
\hline & 2009 & 98 & 100 & 167 & 52 & 417 \\
\hline & Total & $\begin{array}{c}188 \\
(22.2 \%)\end{array}$ & $\begin{array}{c}199 \\
(23.5 \%)\end{array}$ & $\begin{array}{c}375 \\
(44.3 \%)\end{array}$ & $\begin{array}{c}83 \\
(9.8 \% \\
)\end{array}$ & 845 \\
\hline \multirow{4}{*}{$\begin{array}{c}\text { Meta. Journal des } \\
\text { Traducteurs } \\
\left.\text { (total = } 191 \text { articles }{ }^{*}\right)\end{array}$} & 2000 & 65 & 34 & 180 & 21 & 300 \\
\hline & 2005 & 673 & 632 & 1587 & 375 & 3267 \\
\hline & 2009 & 265 & 236 & 551 & 117 & 1169 \\
\hline & Total & $\begin{array}{c}1003 \\
(21.1 \%)\end{array}$ & $\begin{array}{c}902 \\
(19 \%)\end{array}$ & $\begin{array}{c}2318 \\
(48.9 \%)\end{array}$ & $\begin{array}{c}513 \\
(10.8 \\
\%)\end{array}$ & 4736 \\
\hline \multirow{4}{*}{$\begin{array}{l}\text { Perspectives. Studies } \\
\text { in Translatology } \\
\text { (total }=51 \text { articles }{ }^{*} \text { ) }\end{array}$} & 2000 & 49 & 62 & 152 & 10 & 273 \\
\hline & 2005 & 65 & 94 & 184 & 23 & 366 \\
\hline & 2009 & 120 & 126 & 256 & 55 & 557 \\
\hline & Total & $\begin{array}{c}234 \\
(19.5 \%)\end{array}$ & $\begin{array}{c}282 \\
(23.5 \%)\end{array}$ & $\begin{array}{c}592 \\
(49.5 \%)\end{array}$ & $\begin{array}{c}88 \\
(7.3 \% \\
)\end{array}$ & 1196 \\
\hline \multirow{4}{*}{$\begin{array}{c}\text { Translator. Studies in } \\
\text { Intercultural } \\
\text { Communication } \\
\left.\text { (total }=49 \text { articles }{ }^{\star}\right)\end{array}$} & 2000 & 104 & 127 & 289 & 62 & 582 \\
\hline & 2005 & 94 & 85 & 266 & 18 & 463 \\
\hline & 2009 & 166 & 134 & 345 & 52 & 697 \\
\hline & Total & $\begin{array}{c}364 \\
(20.8 \%)\end{array}$ & $\begin{array}{c}346 \\
(19.8 \%)\end{array}$ & $\begin{array}{c}900 \\
(51.6 \%)\end{array}$ & $\begin{array}{c}132 \\
(7.5 \% \\
)\end{array}$ & 1742 \\
\hline TOTAL & & $\begin{array}{l}1789 \\
21 \%\end{array}$ & $\begin{array}{c}1729 \\
20.2 \%\end{array}$ & \begin{tabular}{|l|}
41859 \\
$49.1 \%$ \\
\end{tabular} & $\begin{array}{r}816 \\
9.5 \% \\
\end{array}$ & 8519 \\
\hline
\end{tabular}

* articles in this cell makes reference to those studied in the corpus.

Table 2. Type of contribution in articles published in 2000, 2005 and 2009

After analysing 326 articles, we have observed little differences among the four different journals of our corpus, and there is no significant variation over 
time. What needs to be highlighted is that books are by and large the most cited kind of contribution in the bibliographies we looked at, with an average percentage approaching the $50 \%$ mark. As regards journal articles and book chapters referenced, both surpass $20 \%$ ( $21 \%$ and $20.2 \%$, respectively). Finally, other kinds of contributions, although much smaller in number, also represent $9.5 \%$ of the total number of references analysed. It would be interesting to investigate further to find out if these figures would show any variation if variables related to country of origin and line of research were included in the analysis, although for reasons of time and space we have to leave this also for future research (14). Attention should also be paid to the new availability of articles via internet, and free access to online journals. There seems to have been a slight shift in the publication landscape in T\&I, but this issue needs further research.

These results pose some questions as far as research assessment is concerned. If, as our analysis has highlighted, $69.3 \%$ of references consulted and cited by researchers within T\&I Studies are books and book chapters, we should assume therefore that the authors find them interesting and useful for their research. If these modes of research dissemination are still recognised as highly valuable by our peers, assessment agencies should rethink their status within quality assessment processes, at least in terms of impact, and maybe should regard them equally as highly as journal articles. Let us not forget that books and book chapters are often peer-reviewed and that due to the global crisis "Getting an academic book published will almost certainly become even more difficult as economic weakness forces universities to make budget reduction, with adverse consequences for libraries and university presses" (Kratoska 2009, p. 3). So, the fact that journal publishing (especially if it is in electronic format) is less costly than books, may also in the medium term lead to a re-evaluation of the assessment of contributions in book format.

While this is not the place to delve into the issue, it is interesting to note the fact that all the journals on T\&I indexed either in Social Science Citation Index (SCCl) or Arts and Humanities Citation Index $(\mathrm{AHCl})$ are in paper format (Desblache forthcoming). We have not found any high impact e-journal, and interestingly, quotes within the articles analysed are not necessarily from journals considered the most prestigious. Some studies on quotes have already 
shown the impact of e-journals. For example Wouters \& de Vries (2004, p. 1251) have demonstrated that they are not only influencing how "scientific and scholarly researchers are organizing their work" but also that it is "clearly becoming the dominant medium for scientific authors and scholars" (ibid, $p$. 1258).

Nevertheless, as this is merely an exploratory study, a qualitative data analysis should be completed to look at issues such as self citing, variety of references, role of e-journals etc. to shed some light on the motivations behind referencing. According to Fry et al $(2009$, p. 35)

\footnotetext{
There have been a number of generally narrowly focussed studies into the motivation behind what an author cites. The findings suggest that the main reasons for referencing are to establish the background and context of a topic, and to then provide supporting evidence. It would appear that personal contact or familiarity with an author can be a major factor in choosing to cite their material. This is likely to increase over time as an academic enlarges their circle of acquaintances within their research area, and is evident in work done on selfcitation networks.
}

To investigate to what extent this is the case within T\&I Studies, we would need to collect data directly from researchers using both qualitative and quantitative methods. A first step towards an adaptation of this indicator for the fields within Social Sciences and Humanities is the information offered in the Catalan agency AQU $(2010$, p. 7) where the tradition of publication in monographs has recently been acknowledged. It is hoped that as a next step, in the near future, they adjust their benchmarking accordingly.

\section{Spanish scholars}

As the authors are within the Spanish and Catalan university education system, we wanted to have a look at how researchers affiliated to Spanish universities performed, in publication terms, in high impact journals.

The percentage of articles written by scholars affiliated to Spanish universities publishing between 2007 and 2009 in the T\&I indexed journals included in our study surpasses the $10 \%$ mark, which in relative terms is not a bad figure. Nevertheless the distribution across publications is uneven. There is not even one paper published by Spaniards in Multilingua. Journal of Crosscultural and Interlanguage communication nor in Translation Review and, 
conversely, Spaniards are highly represented in other journals, such as the Interpreter and Translator Trainer (23.5\%) and in Perspectives. Studies in Translatology (17.7\%).

It would be interesting to understand the reasons behind these figures, and why Spanish academics might favour, one journal in particular over another. It could be the case that researchers publish in journals with which they are personally familiar, either because they read them regularly or because they know a person either on the editorial board or someone who has already published there. So, to some extent, it is possible that physical proximity (in the broad sense of the term) and networking play an important role when researchers select a journal to whom they submit their papers - time delay in the publication frequency is another of the more important determining factors.

It could also be the perception that Spanish scholars have of certain journals. Matarese (2008) has established a link between the quality of the style sheet and instructions to authors and the related editorial policy in the sense that authors turn to journals which they consider as 'serious'. Matarese (ibid) also believed that comprehensive instructions implied professionalism and rigour, and that this in turn had a direct relationship with the quality of "editorial leadership". Perspectives: Studies in Translatology, for example, may be favoured because of the rapid turnaround and the wide distribution offered by the Taylor \& Francis Group.

In other studies, such as Sønderstrup-Andersen and SønderstrupAndersen's (2008, p. 401), the choice of journals that a researcher makes has been directly linked to the so-called impact factor as "a series of journals correlates significantly to the respondents' preferences for publication - the higher the JIF (Journal Impact Factor) the more the researchers wish to publish in those journals". These two comments should be regarded with some caution as we have not found any T\&I journal with JIF for the year 2008 and the only T\&I journal included in the JCR (Journal Citation Reports) is The Interpreter and Translator Trainer (only for 2007)(15). Articles published after 2007 will need a few more years to be properly accounted for and may be without any citations: this factor is influenced both by the years selected as well as the journals found in the database from which citations are taken. None of the journals in our T\&l journal list is likely to have an impact factor, so we do not believe therefore that 
the JIF parameter is what researchers in our area have in mind when choosing a publication. What can be affirmed at this point is that most researchers within T\&I studies who need to be assessed for promotion do check if journals are at least indexed in main indexes and databases before selecting them as the vehicle to publish and disseminate their research results. Similarly, Fry et al (2009, p. 43) affirm that "A barrier to publishing articles in high impact factor journals is competition for limited resources and subsequent publication lags, but nonetheless motivation to publish in as high-ranked journals possible seems high amongst researchers".

On the other hand, Swan's (2008, p. 64) study for the JISC Scholarly Communications Group found that an important motivating factor for disseminating research in one journal over another was to gain peer esteem regardless of whether or not the journal in question had a high impact factor.

Significantly, almost all researchers say that when they are choosing a journal in which to publish their work they wish to publish in one that has the right audience. They also say that this does not always tally with journals that have the highest impact factors in the field. Publishing in high-JIF journals brings greater rewards in terms of formalised research assessment processes but publishing in journals that reach the right audience brings reward in terms of recognition by peers. (Swan's 2008, p. 64)

It should be noted that recognition by peers can eventually become a tangible reward as it increases the probability of being cited. As the number and quality of citations is one of the ways in which research impact and research excellence is measured in Spain, researchers are faced with the following dilemma: publish in high rank journals and take the risk of not reaching the right audience and thus not being cited, or publish in "second-tier" journals and take the risk of not being indexed but ensuring they will reach the right audience and thus increase the possibility of being cited.

It would be interesting to understand if within the field of T\&I there is a direct correlation between high impact factor and the language or geographical scope of journals. According to Van Teijlingen and Hundley (2002) and Macdonald and Kam (2007a; 2007b) articles submitted to high impact journals must fit the scope of certain editorial leadership. This may mean the rejection of novel research, research which challenges main stream theories, interdisciplinary 
research, multidisciplinary research or certain language pairs. Hence contributions to certain high impact journals will follow a certain ideological strands. This effect has already been studied by Chubin and Hackett (1990; 2003) and Crane (1976) and it is summarized by Lamont (2009, p. 2) as "Peers monitor the flow of people and ideas through the various gates of the academic community... and some peers are given more of a voice than others, and serve as gatekeepers more often than others". In this respect, one comment we can make relevant to T\&I Studies comes from our direct personal experience. After sending an article to Translation Review, tackling the issue of Chinese-Catalan translation problems, one of the authors was informed that the journal was only interested in works dealing with English as a target language, although this precondition was nowhere to be found in the author's guidelines.

\section{Two practical cases which illustrate the gap between the existing}

\section{benchmarks and their application}

An interesting exercise, albeit perhaps too superficial or anecdotal with which to draw conclusions, is to look at some negative evaluation comments extracted from real life reports from the Spanish quality agency ANECA where a researcher presented five contributions for a research assessment exercise. From amongst the assessors' comments that were received we have extracted some examples of particular relevance to the scope of the present article:

- The committee justifies the low grade awarded to two of the contributions because of the number of pages, and with regards to the third contribution - that which explains how to analyse a text in the first stage of the translation process, it is pointed out that "this is not considered a work of research in the field of Translation".(16)

- Regarding contributions 1 and 4, they have been marked respectively with 5 and 4 points out of 10 because the number of authors [2] is considered to be excessive given the complexity and length of the contribution (8 and 5 pages respectively).(17)

The report was appealed with the following arguments: 
- Eight pages are the maximum accepted by the journal where the article was published.

- The authors had to specifically reduce their work to the requested 7200 characters, and with the added editorial warning: the length must not exceed five pages.

- One of the authors for one of the contributions was awarded 3 points out of the possible 10 , whereas the other author of the same contribution was awarded 4.5 marks.

Ultimately the appeal was successful and the final assessment was positive. The many subjective issues raised by the evaluator were successfully counterargued by the author. This example, which unfortunately is not an exception has illustrated the subjective nature of what is a crucial decision in some cases, with potentially far reaching impacts on a given researcher's ability to successfully attain an academic post.

In a further example, the Catalan Quality Agency rejected a research CV for a research assessment exercise saying "some of the contributions were published by their own research institution. The rest of the merits do not compensate for the deficiencies in the CV".(18) After a period of appeal the same agency replied "once the merits were reviewed, and after taking into consideration the candidate's statements, and based on the criteria applied by the commission, it has been considered that the merits presented by $\operatorname{Dr} \mathrm{X}$ are innovative and have fulfilled the requested level and hence has obtained a positive assessment".(19) We could now embark on a discussion of the definition of innovation, originality and how to measure them objectively, but given the length and scope of this article these issues will also remain for future research.

\section{Conclusions}

This contribution has shined a light on a new area of research in Translation Studies: bibliometrics. It should pave the way to the creation of a much needed critical mass in the field of Translation research, detached from Applied Linguistic, Modern Languages, Philology or Comparative Literature. Still some caution should be taken with data and results gathered in an automatic fashion, 
as Gile (2008) clearly comments "My view is that present scientometric work, and especially thorough exploratory work such as valiantly conducted by Grbić \& Pöllabauer is both commendable and valuable, but that in TS, a mix of such work and 'manual' work which include careful consideration of qualitative aspects of the phenomena under study is required to provide the best answers to research questions."

Although the article has focused on Spanish and Catalan data, a similar analysis can be extrapolated to any country as publishing or perishing is now the international trend, and scholars across Europe, for example, are going through almost identical assessment exercises. Besides the thorny issues highlighted within this article, we have identified two possible outcomes from our resulting data, particularly referring to those cases where the data does not match the published benchmarks:

a) Evaluating agencies have a latent or hidden policy in influencing the research agenda. This may lead towards a homogenisation of the research approach across disciplines, which will be in direct contradiction with the function of universities, which Chomsky (1973, p.135) described thirty years ago as:

The university should be a center for radical social inquiry... It should loosen its 'institutional forms' even further, to permit a richer variety of work and study and experimentation, and should provide a home for the free intellectual, for the social critic, for the irreverent and radical thinking that is desperately needed if we are to escape from the dismal reality that threatens to overwhealm us.

b) The gap between what is expected from researchers and how research is evaluated is an open and contentious issue. The gap may be bridged to adapt to field specificities. Evaluating agencies should be open to the idea of adapting their published and applied criteria, and agree to do so.

The main aim of the article was to provide a thought provoking and practically useful paper for all facing a research assessment, be it in Spain, Catalonia or any other country. Though specific and local benchmarking may vary, a trend towards homogeneity across disciplines and countries is spreading rapidly. There is also an underlying issue whereby the model of perish or publish is usurping previous academic traditions, where quality seems to be regarded as an objective and quantifiable concept - measurable through scientific means. While the concept of 'Quality Assessment' in the field of 
Humanities and Social Sciences may be an oxymoron to many researchers, if we are doomed to this faith, we should request clearly established and accepted parameters with supporting guidelines and protocols openly published.

Within Humanities and Social Sciences there are clearly identifiable differences in patterns of research typology and dissemination across disciplines, and as such evaluators should apply flexible assessment guidelines and adapt criteria to the real practices in each discipline. In this respect, an index or database listing all academic journals in T\&I Studies and related areas resulting from consensus among scholars within our research area is urgently needed. Indeed evaluators should ideally belong to the field they are assessing and have regular training in order to keep abreast of the changing nature of research, new research trends and methodologies and their impact.

\section{Bibliography}

Aguirre, Joaquín M. (2009). "Crisis y editoriales". Espéculo 43 http://www.ucm.es/info/especulo/numero43/43editor.html [Consulted on $17 / 2 / 2010]$

AHRC (2009). Leading the world: the economic impact of UK arts and humanities research. Available from http://www.ahrc.ac.uk/About/Policy/Documents/leadingtheworld.pdf [consulted 1.1.2010]

ANECA (2008). Programa academia Principios y Orientaciones para La aplicación de los criterios de Evaluación. V. 1.0 9/01/2008. Accessed from http://www.aneca.es/media/323068/academia_principios_y_orientaciones 080114.pdf [consulted 5.1.2010]

AQU (2007). Tenure-track Lecturer and Collaborating Lecturer Committee. http://www.aqu.cat/doc/doc_19322886_1.pdf [consulted 14.2.2010]

AQU (2008). Research Assessment Committee Criteria for the issue of advanced research accreditations. Available from http://www.aqu.cat/doc/doc_26243458_1.pdf [consulted 1.1.2010]

AQU (2010). L'avaluació de la recerca en Humanitats i Ciències Socials. Xlè Taller de reflexió i debat d'AQU Catalunya amb les universitats catalanes. niversitat de Barcelona, 28 i 29 de gener de 2010. Available from http://www.aqu.cat/doc/doc 16407351_1.pdf [consulted 12.7.2010]

Becher, T. and Trowler, P.R. (2001). Academic tribes and territories: intellectual enquiry and the cultures of disciplines. Buckingham: Open University Press. (2nd Revised Ed)

Chomsky, Noam (1973). "The Function of the University in a Time of Crisis". In For Reasons of State. New York: Pantheon Books. 
Chubin, Daryl E. \& Edward J. Hackett (1990). Peerless Science: Peer Review and U.S. Science Policy. Albany: State University of New York Press.

Chubin, Daryl E. \& Edward J. Hackett (2003). Peer Review of the Twenty-first Century: Applications to Education Research. Report prepared for National Research Council, Washington, D.C.

Collini, Stefan (2009). "Impact on Humanities". http://entertainment.timesonline.co.uk/tol/arts_and_entertainment/the_tls/a rticle6915986.ece [Consulted on 17/11/2009]

Crane, Diane (1976). "Network, Norms and Trust: The Social Psychology of Social Capital". Social Psychology Quarterly 68 (1), 4-14.

Cronin, B. (2003). "Scholarly communication and epistemic cultures". New Review of Academic Librarianship, 9(1), 1-24.

Desblache, Lucile (forthcoming) "Mapping digital publishing for all in translation". In Carroll, Mary, Pilar Orero \& Aline Remael (eds) Media for All 3. Quality Made to Measure. Amsterdam: Rodopi.

Engers, Maxim, Joshua S. Gans, Simon Grant, and Stephen P. King (1999) "First-author conditions". Journal of Political Economy 107, 859-83.

Fernández Beltrán, Francisco (2009). "Los hechos de la edición universitariay el camino de la excelencia". UNE 19: 2 http://www.une.es/(A(NsqYu7EygEkAAAAYzExNzhmOTctMjcyMy00NGFhLWFINjctYTRIOGFhO TgxZmZj90nOS4p_HOpiGIRx6zzbAO3fpWQ1))/Ent/Items/ItemDetail.aspx? ID $=2885$ [consulted on 17/2/2010]

Franco Aixelá, Javier \& Pilar Orero (2005): "Research on audiovisual translation: some objective conclusions, or the birth of an academic field." In John Sanderson (ed.) Research on Translation for Subtitling in Spain and Italy: Alicante: Universidad de Alicante, 79-92.

Fry, Jenny, Charles Oppenheim, Claire Creaser, William Johnson, Mark Summers, Sonya White, Geoff Butters, Jenny Craven, Jill Griffiths, and Dick Hartley (2009). Communicating knowledge: How and why UK researchers publish and disseminate their findings. The Research Information Network (RIN) and the Joint Information Systems Committee (JISC).

http://www.jisc.ac.uk/media/documents/publications/communicatingknowl edgereport.pdf [consulted on 31.12.2009]

Gile, Daniel (2000). "The history of research into conference interpreting: A scientometric approach." Target 12 (2), 297-321.

Gile, Daniel (2005). "Citation patterns in the T\&I didactics literature". Forum 3 (2), 85-103.

Gile, Daniel (2008). CIRIN. Bulletin 37, December 2008.

Grbic, Nadja. (2007). Where do we come from? What are we? Where are we going? A bibliometrical analysis of writing and research on sign language interpreting." The Sign Language Translator \& Interpreter 1 (1), 15-51.

Grbic, Nadjia \& Sonja Pöllabauer (2008a). "Counting what counts: Research on community interpreting in German-speaking countries - A scientometric study". Target 20(2), 297-332.

Grbic, Nadjia \& Sonja Pöllabauer (2008b). "To count or not to count: Scientometrics as a methodological tool for investigating research on translation and interpreting". Translation and Interpreting Studies 3 (1-2), $87-146$. 
Grbic, Nadjia \& Sonja Pöllabauer (2009). "An author-centered scientometric analysis of Daniel Gile's oeuvre". In Gyde Hansen, Andrew Chesterman, and Heidrun Gerzymisch-Arbogast (Eds). Efforts and Models in Interpreting and Translation Research. Amsterdam: Benjamins, 3-24.

Harzing, Ann-Wil (2010a). "Citation analysis across disciplines: The Impact of different data sources and citation metrics". http://www.harzing.com/data_metrics_comparison.htm [consulted on 6.7.2010]

Harzing, Ann-Wil (2010b). The Publish or Perish Book. Melbourne: Tarma Software Research Pty Ltd.

Kissan, Joseph, David N. Laband and Vivek Patil (2005). "Author Order and Research Quality”. Southern Economic Journal, Vol. 71, No. 3 (Jan., 2005), 545-555

Kratoska, Paul H. (2009) "The scholar's choice and the scholar's dilemma". ICAS 6, 2-3.

Lamont, Michèle (2009). How Professors Think. Inside the Curious World of Academic Judgment. Cambridge, MA: Harvard University Press.

Macdonald, S. and Kam, J. (2007a). "Aardvark et al.: quality journals and gamesmanship in management studies". Journal of Information Science, 33(6), 702-717.

Macdonald, S and Kam, J. (2007b). "Ring a ring o' roses: quality journals and gamesmanship in management studies". Journal of Management Studies, 44(4), 640-655.

Matarese, V. (2008). "Relationship between Quality and Editorial Leadership of Biomedical Research Journals: A Comparative Study of Italian and UK Journals". PLoS ONE 3(7): e2512.

Over, Ray, and Susan Smallman (1973). "Maintenance of individual visibility in publication of collaborative research by psychologists". American Psychologist 28,161-6.

Pöchhacker, Franz (1995). "Writings and research on interpreting. A bibliographic analysis." The Interpreters' Newsletter 6, 17-32.

Rovira-Esteva, Pilar Orero (forthcoming). "Evaluating Quality and Excellence in Translation Studies Research: Publish or Perish, the Spanish Way".

SCImago. (2007). SJR - SClmago Journal \& Country Rank. http://www.scimagojr.co [consulted 1.1.2010]

Sønderstrup-Andersen, E.M. and Sønderstrup-Andersen, H.H.K. (2008). "An investigation into diabetes researcher's perceptions of the Journal Impact Factor - reconsidering evaluating research". Scientometrics, 76(2), 391406.

Swan, A. (2008). The 'big picture' and researchers' key concerns within the scholarly communication process: report to the JISC scholarly communications group. Accessed from http://eprints.ecs.soton.ac.uk/15450/2/Researchers\%27 top_concerns_rep ort final version April 08.pdf [consulted 1.1.2010]

Van Teijlingen, E. and Hundley, V. (2002). "Getting your paper to the right journal: a case study of an academic paper". Journal of Advanced Nursing, 37(6), 506-511.

Wouters, P. and de Vries, R. (2004). "Formally citing the web". Journal of the American Society for Information Science and Technology, 55(14), 12501260. 


\section{Endnotes}

1 This research has been partly funded by the Spanish Ministry Project reference FFI2008-05911 (sub programme FISO) and also by the Catalan Research Group reference 2009SGR 1103.

2 This research has been partly funded by the Spanish Ministry Project reference FFI2009-08027 (sub programme FILO) and also by the Catalan Research Group reference 2009SGR700.

${ }^{3}$ What is meant here is that some of these journals do not focus exclusively on T\&I Studies but often publish related contributions.

${ }^{4}$ These two indexes are the only ones explicitly mentioned by the three quality agencies (AQU, ANECA and CNEAI) (see Rovira-Esteva and Orero, forthcoming).

${ }^{5}$ The following volumes have not been included in our study because they had not yet been published when this researched was being carried out: Meta Journal des Traducteurs 2009, 54(4); and Translation Review 2009.

${ }^{6}$ This column only applies to multi author articles.

${ }^{7}$ Each article with at least one author belonging to a Spanish university counts one (thus, various authors count only one).

${ }^{8}$ It now belongs to the Taylor \& Francis Group.

9 The scope of research in T\&I Studies would be considered under Becher and Trowler (2001: 106) terminology as 'rural'. The 'urban' researcher works in a narrow area of study, containing discrete and separate problems, "clustered around a few salient topics" while the 'rural' researcher typically covers a broader area of intellectual territory in which problems are not sharply demarcated or delineated, but "spread out across a wide range of themes".

10 The authors of this article and previous joint work have violated alphabetical order. In our case the conscious decision was made in order to secure credits to the first researcher, since she is 13 years junior to the second signature.

${ }^{11}$ While this information is yet another issue to take into consideration, it falls outside the scope of this article. Nevertheless some interesting data is quite telling. Becher \& Trowler found that publication delay in Physics is from $9-12$ months, similar Economics 9 - 18 months, but different from Linguistics 2 - 3 years, (although publication in a less prestigious journal could reduce this to 6 months) and History and Sociology 18 months -2 years (Becher \& Trowler 2001:112) who comment "The delay in getting work published was seen as indicative of the level of competitive pressure within a research area, whereas the nature and scale of research topics were reflected in the length and frequency of research output" (ibid).

${ }^{12}$ Against the Catalan cryptic message we find the clear note by the Spanish agency (ANECA 2008: 14) "in any case, articles published in prestigious journals will be preferred" [en cualquier caso, se valoran preferentemente las aportaciones que sean artículos en revistas de reconocido prestigio] (our translation).

${ }^{13}$ Translation Review has been excluded from this analysis because apparently the editorial policy does not oblige authors to include a specific section with a reference list.

14 According to general data from the Catalan agency AGAUR, the average output format from 2005 to 2008 of the research groups officially recognised by 
the Catalan government is as follows: $47 \%$ articles (with only one half published in indexed journals), $11 \%$ books and $41 \%$ book chapters.

${ }^{15}$ Although it's direct and powerful competitor, the so-called SJR (SCimago Journal \& Country Rank) (see: http://www.scimagojr.com/index.php), does include T\&l journals this tool is still hardly known by researchers and not freely open to access.

${ }^{16}$ El comité justifica la baja puntuación asignada a dos de las aportaciones aludiendo al número de páginas que éstas contienen y, en el caso de una tercera aportación, en la que se explica cómo analizar un texto en la primera fase del proceso de traducción, se señala que "no se concibe como un trabajo de investigación en el campo de la traducción". (Our translation).

${ }^{17}$ Por lo que respecta a las aportaciones, la número 1 (Artículo: $O$ mundo das axencias de traducción en Galicia) y 4 (Artículo: Tratamiento del lenguaje del niño y de sus juegos en la traducción: The Giver y sus versiones en español y en gallego) han sido calificadas con 5 y 4 puntos respectivamente porque, según la Comisión, "El número de autores se considera excesivo para la complejidad y extensión del tema (8 y 5 páginas respectivamente)". (Our translation).

${ }^{18}$ En el seu cv abreujat, la sol-licitant aporta contribucions que no poden ser considerades com a ordinàries d'acord amb la resolució (...) i altres estan publicats per la seva pròpia institució de recerca. La resta de mèrits aportats no compensen les mancances observades. (Our translation).

${ }^{19}$ Un cop revisats els mèrits que consten el currículum de la persona recurrent, vistes les seves allegacions i d'acord amb els criteris aplicats per la comissió esmentada, es considera que les aportacions de la doctora $X$ són innovadores i assoleixen el nivell de sufiència establert per a l'obtenció d'una valoració favorable. (Our translation). 